\title{
Trap for MAbs: Characterization of Intact Monoclonal Antibodies Using Reversed-Phase HPLC On-Line with Ion-Trap Mass Spectrometry
}

\author{
John C. Le and Pavel V. Bondarenko \\ Department of Pharmaceutics and Drug Delivery, Amgen Inc., Thousand Oaks, California, USA
}

For the first time, the characterization of intact 150-kDa monoclonal antibodies (MAbs) using a commercially available three-dimensional ion-trap mass spectrometer (IT-MS) is reported. The IT-MS analysis was performed on-line with reversed-phase high performance liquid chromatography (RP-HPLC) on a POROS column using a nontraditional solvent system of acetonitrile, isopropanol, ethanol, and water in formic acid. The operating parameters of the IT-MS were optimized by extending the mass range to $\mathrm{m} / \mathrm{z} 4000$ and elevating the tube lens offset voltage value to around $-100 \mathrm{~V}$. Mass accuracy better than $300 \mathrm{ppm}( \pm 40 \mathrm{Da})$ has been routinely achieved for these macromolecules. Multiple peaks $162 \mathrm{Da}$ apart due to the hexose variants of the monoclonal IgG antibodies were partially resolved in mass spectra. Several commercial and chimeric antibodies have been investigated in this study. (J Am Soc Mass Spectrom 2005, 16, 307-311) (c) 2004 American Society for Mass Spectrometry

$\mathrm{T}$ The human monoclonal immunoglobulin $\gamma(\operatorname{IgG})$ molecule is the most popular modality in the modern protein pharmaceutics because of its controlled functions, predictable physiochemical properties, and long life in circulation [1]. Monoclonal antibodies (MAbs) have been successfully commercialized in the biotechnology field for the past ten years. These products have emerged as primary protein therapeutic research and development platforms. Although antibodies have structural similarities, their post-translational modifications on heavy and light chains require constant monitoring from cell culture to final formulated products. Thus, it is obvious that the analysis of intact therapeutic monoclonal antibodies by reversedphase (RP) high-performance liquid chromatography (HPLC) online with mass spectrometry (LC/MS) would dramatically reduce sample preparation and data interpretation and also minimizes putative modifications that may occur during sample preparation, such as during peptide mapping experiments after enzymatic digestion [2].

In recent years, electrospray mass spectrometry (ESIMS) [3], techniques to obtain maximum sample transfer efficiency $[4,5]$ and combination of ionization modes and mass analyzers [6] have enhanced the ability to characterize small to medium sized proteins $(<100$

Published online January 14, 2005

Address reprint requests to J. C. Le, Department of Pharmaceutics and Drug Delivery, Amgen Inc., One Amgen Center Drive, Thousand Oaks, CA 91320-1789, USA. E-mail: johnl@amgen.com
$\mathrm{kDa}$ ) by mass spectrometry. However, matrix-assisted laser desorption/ionization time-of-flight (MALDITOF) $[7,8]$, ESI orthogonal-TOF $[9,10]$ and ESI quadrupole $[2,11-13]$ mass spectrometers have been the instruments of choice for MAbs and macromolecules, largely due to the large $\mathrm{m} / \mathrm{z}$ range of the TOF and high ion transmission efficiency of the quadrupole mass analyzers. Unfortunately, on-line RP-HPLC has not accompanied these previous studies of intact monoclonal antibodies.

Reversed-phase liquid chromatography is an important component of intact protein analysis because it has the ability to separate species based on minor structural heterogeneity and, coupled to standard HPLC detectors, provides quantitative information about the main component, variants, and cleavage products. Because of the large size and hydrophobic nature of antibodies, employment of reversed phase liquid chromatography on-line with mass spectrometry for the analysis of intact antibodies has recently been developed in our laboratories [14-16]. Until recently, perfusion chromatography utilizing highly cross linked polystyrene-devinylbenzene (POROS) resins has often been used for separation and purification of antibodies [17, 18]. This technique suffers from limited separation efficiency attributable to high flow rates of $0.5-3.0 \mathrm{~mL} / \mathrm{min}$ required for separation and signal suppression due to trifluoroacetic acid (TFA)-containing mobile phases (acetonitril/water/TFA) which is not the most popular solvent for electrospray ionization of proteins [19]. Thus, an alternate combination of mobile phase consist- 
ing of ethanol/propanol/formic acid was employed as Solvent B for RP LC/MS analysis of glycosylated peptides [20].

Since the invention [21] and pioneering works of Wolfgang Paul on the three-dimensional quadrupole ion-trap (QIT) [22], numerous landmark research papers have described interesting modes of operation and demonstrated a variety of specific applications [23-26] that illustrate the usefulness of this nascent type of mass spectrometry, especially for small molecules and peptides. Unfortunately, without RP-HPLC, the analysis of intact antibody [27] has required a tedious combination of analytical techniques and extensive modifications of the ion trap analyzer. The main reasons for the lack of published material is thought to be attributable first, to the well recognized limitations of the ion-trap mass spectrometers to detect highly charged ions of MAbs due to the space charge issues [28], and second, several suitable solvent systems and optimal ionization voltages must be determined to deliver intact antibodies and to initiate the ionization process in the ion source region (spray needle ["nozzle"]/skimmer) of an iontrap mass spectrometer, respectively. This is the first report about analysis of intact monoclonal antibodies by electrospray ionization on a commercial three-dimensional quadrupole ion trap mass spectrometer coupled with RP-HPLC (IT-LC/MS). This innovative technique was achieved by interfacing a POROS column that is operated in reversed-phase mode using nontraditional solvents of acetonitrile, isopropanol, ethanol and water in formic acid (FA). The RP-HPLC system first allowed us to obtain acceptable chromatographic resolution of intact antibodies and their degradation products or clip forms. More importantly, molecular masses of the intact antibodies were obtained with unprecedented accuracy by optimizing the tube lens offset voltages and automatic gain control (AGC) to obtain maximum sample transfer efficiency while perhaps minimizing space charging effects.

\section{Experimental}

A commercial IgG1 antibody Herceptin (calculated MW $=148,058 \mathrm{Da}$, Genentech, San Francisco, CA) [29] ${ }^{\circ}{ }^{\circ}{ }^{\circ} \mathrm{a}$ chimeric IgG2 antibody produced at Amgen (calculated $\mathrm{MW}=147,353 \mathrm{Da}$, Amgen Inc., Thousand Oaks, CA) were used in this study. The IgG2 antibody was subjected to an accelerated stability study under elevated temperatures, which caused degradations of the molecule. The HPLC system consisted of a HP-1100 (Agilent, Palo Alto, CA) equipped with a heated $75^{\circ} \mathrm{C}$ POROS R1/10 1-1014-24 (Applied Biosystems, Framingham, MASS) analytical column $(4.6 \mathrm{~mm} \times 50 \mathrm{~mm})$ and operated at a flow rate of $450 \mu \mathrm{L} / \mathrm{min}$. The RP-HPLC system was connected on-line to a Thermo Finnigan LCQ DECA ion trap spectrometer equipped with an off-axis electrospray ionization (ESI) source. Ten $\mu \mathrm{g}$ aliquots of the antibodies were injected per analysis. The IgG1 antibody, Herceptin, was evaluated by IT-
LC/MS utilizing an elution composition of $0.08 \%$ aqueous FA (Solvent $\mathrm{A}$ ) with a linear gradient of acetonitrile/ethanol $(8: 2 \mathrm{vol} / \mathrm{vol})$ in $0.08 \% \mathrm{FA}$ (Solvent B). After a 3 min isocratic hold, a linear gradient started at $20 \% \mathrm{~B}$ and increased to $55 \% \mathrm{~B}$ in $12 \mathrm{~min}(2.92 \% \mathrm{~B} / \mathrm{min})$ followed by an isocratic hold for $3 \mathrm{~min}$. The column was then further washed to $98 \% \mathrm{~B}$ in an additional $12 \mathrm{~min}$ $(3.58 \% \mathrm{~B} / \mathrm{min})$ of a $30 \mathrm{~min}$ gradient. This solvent/ gradient system is referred here as ACN/ETOH containing. It is noticed that IgG1 fractionate differently than IgG2 antibody with this solvent/gradient system.

To effect acceptable resolution and separation of IgG2 antibody preparation, our laboratory evaluated many mobile phase solvent systems. One of the better mobile phase solvent systems for an IgG2 chimeric antibody was ACN/IPA/ETOH/WA, which was composed of the following: 0.08\% aqueous FA (Solvent A) and acetonitrile/ isopropanol/ethanol/water (6.0:1.5:1.5:1.0 vol/vol/vol/ vol) in $0.08 \%$ FA (Solvent B). Following an isocratic post-injection hold, $5 \mathrm{~min}$, the linear gradient started at $25 \%$ B was increased to $60 \%$ B within 15 min and held for $5 \mathrm{~min}$. The column was then washed to $98 \%$ B $(2.53 \%$ $\mathrm{B} / \mathrm{min}$ ) for the next $15 \mathrm{~min}$ of a $40 \mathrm{~min}$ gradient. Depending upon the types of antibodies and their specific formulation buffers, the column wash cycle could take $30 \mathrm{~min}$.

The ion trap LCQ Deca mass spectrometer was operated under Xcalibur 1.2 software (Thermo Finnigan, San Jose, CA). The mass range of $1200-3800 \mathrm{~m} / \mathrm{z}$ was calibrated in the positive ion mode with multipleion monitoring of four ions signals of $[\mathrm{M}+7 \mathrm{H}]^{7+}=\mathrm{m} / \mathrm{z}$ 1730.0, $[\mathrm{M}+6 \mathrm{H}]^{6+}=m / z$ 2018.5, $[\mathrm{M}+5 \mathrm{H}]^{5+}=m / z$ 2421.8, $[\mathrm{M}+4 \mathrm{H}]^{4+}=\mathrm{m} / \mathrm{z} 3026.0$ of a truncated form $\left(\mathrm{MW}:{ }^{\circ} 12,103^{\circ} \mathrm{Da}\right)^{\circ}$ of $^{\circ} \mathrm{a}^{\circ} \mathrm{sTNF}^{\mathrm{R}} 1^{\circ}$ protein $^{\circ}[30]^{\circ}$ for ${ }^{\circ}$ this study instead of polypropylene glycol (PPG). Mass spectra of both IgG1- and IgG2 antibody analyses were acquired over a range from $\mathrm{m} / \mathrm{z} 2100-3800$. The mass spectrometric acquisition required the tube lens offset voltage was set at $-100 \mathrm{~V}( \pm 25 \mathrm{~V})$. The voltage of the ion-spray needle was $5000 \mathrm{~V}( \pm 200 \mathrm{~V})$ and the temperature of the heated capillary was $280\left( \pm 20^{\circ} \mathrm{C}\right)$. The AGC setting of full mass was occasionally changed to 5 $\times$ E8 from conventional setting of $5 \times$ E7. Other targets and duration of micro-scan were approximately at their default values.

\section{Results and Discussion}

Since the amino acid sequences of antibodies used in this report are known, the purpose of this study was to confirm unambiguously the molecular weight of these antibodies $^{\circ}$ by $^{\circ}$ IT $^{\circ}$ LC MS. ${ }^{\circ}$ Figure $^{\circ} 1 a^{\circ}$ shows $^{\circ}$ an HPLC-UV chromatogram of the IgG1 (Herceptin) antibody ${ }^{\circ}$ after ${ }^{\circ}$ separation ${ }^{\circ}{ }^{\circ}{ }^{\circ}$ OROS $^{\circ}$ column $^{\circ}$ Figure ${ }^{\circ} 1 b^{\circ}$ is $^{\circ} a$ positive ion ESI mass spectrum of the main chromatographic peak acquired in the range from $\mathrm{m} / \mathrm{z} 2400-3500$ and featuring multiply charged ions from $44+$ to $60+$. Figure $^{\circ} 1 \mathrm{c}^{\circ}$ shows $^{\circ}$ the ${ }^{\circ}$ convoluted $^{\circ}$ and $^{\circ}$ deconvoluted $^{\circ}$ ESI mass spectrum of IgG1 antibody with resolving masses 148,098 and $148,260 \mathrm{Da}$. The difference in mass of $\sim 162$ 

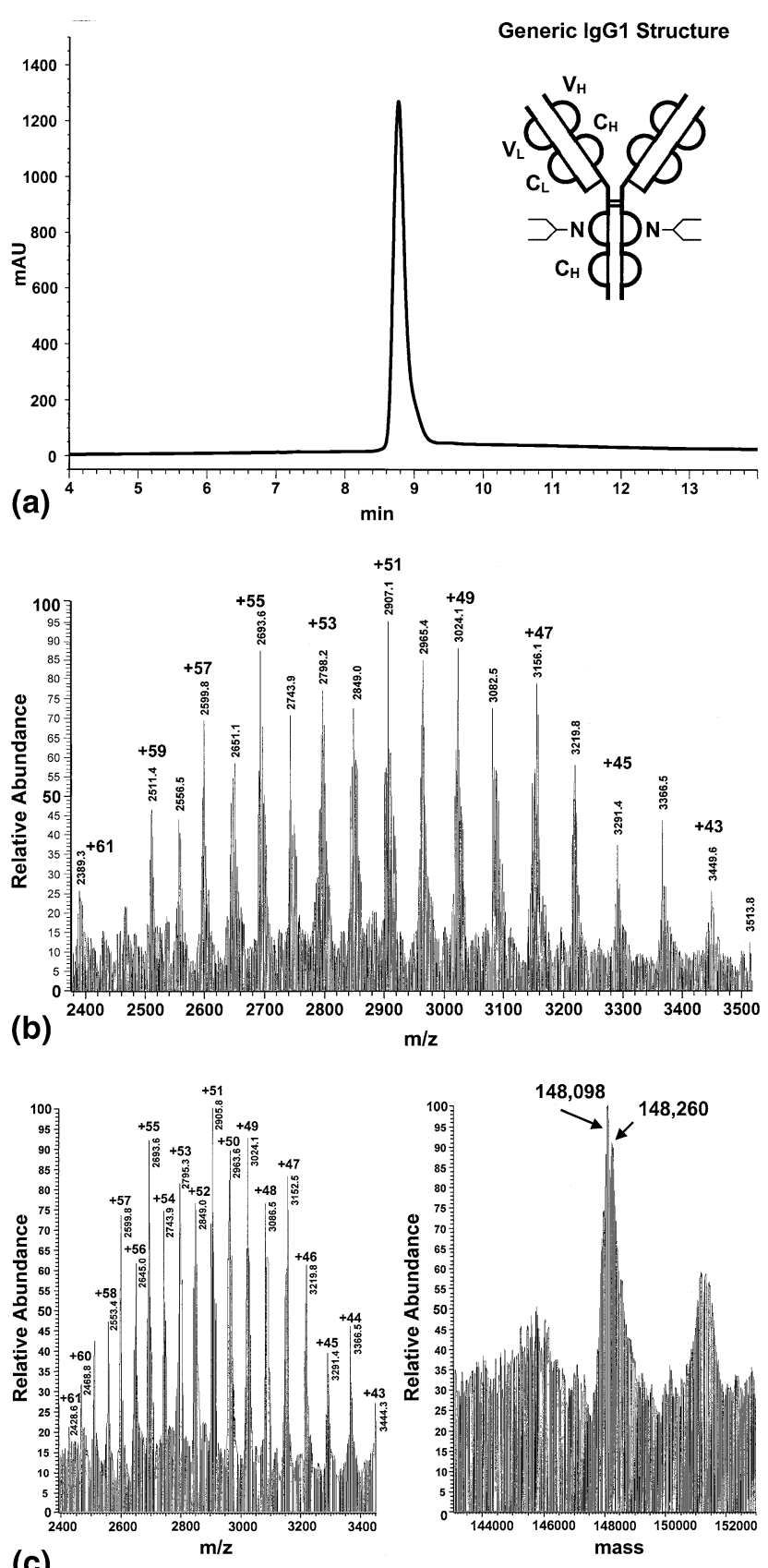

(c)

Figure 1. (a) A RP-HPLC chromatogram of an IgG1 antibody used in this study with UV detection at $215 \mathrm{~nm}$. Inset shows a generic schematic of IgG1 antibody. (b) An expended positive ESI mass spectrum of intact IgG1 antibody Herceptin from $\mathrm{m} / \mathrm{z} 2400-$ 3500 with charged ions ranging from $43^{+}$to $61^{+}$. The spectrum was reconstructed by removing excessive noise signals and artifacts caused by the application software. (c) The corresponding convoluted and deconvoluted mass spectra (reconstructed) of Herceptin antibody and its associated structural micro-heterogeneity: 148,098 Da and 148,260 Da, respectively. The observed mass difference of $162 \mathrm{Da}$ is correlated with a loss of a hexose residue (Hex, $162 \mathrm{Da}$ ), which is a typical heterogeneity of glycosylation observed in IgG antibodies produced in mammalian cells.

Da correlated with a loss of a hexose residue (Hex), which is a typical heterogeneity of glycosylation observed in IgG antibodies produced in mammalian cells [13]..$^{\circ}$ When ${ }^{\circ}$ the ${ }^{\circ}$ same $^{\circ} \mathrm{ACN} /$ ethanol $^{\circ}$ containing $^{\circ}$ mobile phase was used for IgG2 antibody, chromatographic resolution efficiency was significantly reduced (data are not shown). To improve eluotropic properties of the mobile phase and obtain better separation of the degradation products of IgG2 antibody, iso-propanol was added to Solvent $\mathrm{B}$. Thus, depending upon the subclass of antibody being examined, IgG1 or IgG2, it would be important to optimize the chromatographic mobile phase ${ }^{\circ}$ to $^{\circ}$ effect $^{\circ}$ maximal ${ }^{\circ}$ resolution. ${ }^{\circ}$ Figures $^{\circ} 1 a^{\circ}$ and ${ }^{\circ} 2 a$ illustrated the need to have a different mobile phase system to obtain better chromatographic resolution for IgG2 antibodies compared to an IgG1.

Figure $2 \mathrm{a}^{\circ}$ shows $^{\circ} \mathrm{an}^{\circ} \mathrm{HPLC} \mathrm{CV}^{\circ} \mathrm{chromatogram}^{\circ}$ of ${ }^{\circ}$ the IgG2 antibody. On the chromatogram, the low MW cleavage products of 12 to $24 \mathrm{kDa}$ (clips) eluting from 9.5 to 9.8 min were chromatographically separated from the high MW components of the degraded IgG2 sample. Because of the limited resolution of the chromatographic peaks eluting from 10.3 to $11.5 \mathrm{~min}$, we were not able to accurately measure the masses of degrada-
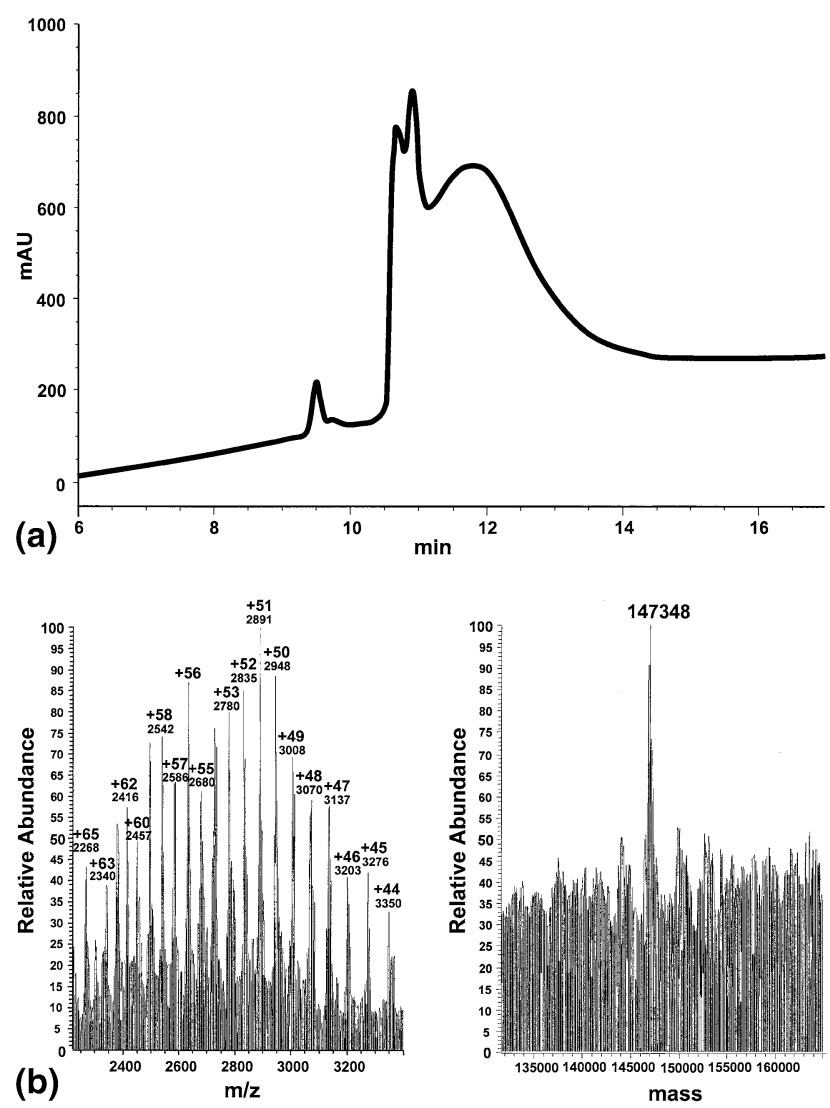

Figure 2. (a) A RP-HPLC chromatogram of an IgG2 antibody used in this study after separation on POROS column with UV detection at $215 \mathrm{~nm}$. The observed multiple degradation products were induced by storage at elevated temperatures over an extended period of time. (b) The corresponding positive ESI mass spectrum of the chromatographic peaks eluting from 11.3 to 13.5 min in (a) featuring multiply charged ions from $44+$ to $63+$. The deconvoluted mass spectrum of the observed mass of 147,348 Da of this IgG2 antibody is closely matched its theoretical mass of $147,353 \mathrm{Da}$. 
tion $^{\circ}$ products $^{\circ}$ or $^{\circ}$ isoforms ${ }^{\circ}$ of $^{\circ}$ this ${ }^{\circ}$ antibody. ${ }^{\circ}$ Figure $2 b^{\circ}$ is a positive ion ESI mass spectrum of the chromatographic peaks eluting from 10.3 to $13.5 \mathrm{~min}$ acquired in the range from $\mathrm{m} / \mathrm{z} 2200-3400$ and featuring multiply charged $^{\circ}$ ions $^{\circ}$ from $^{\circ} 44+{ }^{\circ}$ to ${ }^{\circ} 63+.^{\circ}$ Figure $^{\circ} 2 c^{\circ}$ shows ${ }^{\circ}$ the deconvoluted ESI mass spectrum of IgG2 antibody in the mass range of the intact molecule with measured mass of 147,348 Da. The glycosylation profile featuring different number of hexoses was not resolved in this case. The measured mass agreed well with the calculated $\mathrm{MW}=147,353 \mathrm{Da}$ for glycosylation structure without any terminal hexoseresidues [13]. These results have been confirmed by size exclusion chromatography and MALDI-TOF analyses in our laboratory (data are not shown). The control experiments confirmed that the degradations products of the IgG2 antibody were indeed caused by the storage conditions and not by the low $\mathrm{pH}$, elevated temperature environment on the POROS column. It was also observed that the multiple chromatographic peaks eluting from 10.3 to $13.5 \mathrm{~min}$ were either obscured or totally hidden when using the mobile phase containing only ACN/ethanol/water/FA combination of solvents. The addition of iso-propanol to our perfusion chromatography system improved separation and elution properties similar to our laboratory experiments on silica based $\mathrm{C} 8$ stationary phases [15]..$^{\circ}$ In $^{\circ}$ this ${ }^{\circ}$ report, ${ }^{\circ}$ the ${ }^{\circ}$ mass $^{\circ}$ accuracy $^{\circ}$ was $^{\circ}$ measured and averaged after three consecutive LC/MS runs for each antibody and it was determined within 300 ppm for IgG1 antibody and 100 ppm for IgG2 antibody.

Our experiments focused on optimization of the IT-LC/MS show that the ion transfer efficiency from atmosphere to the ion trap could be greatly improved by increasing amplitude of the tube lens offset voltages. The tube lens voltage provides the potential voltage drop to accelerate the highly charged ions during the ionization spray processes by confining and focusing them at the entrance of the ion-trap skimmer after they exist $^{\circ}$ the ${ }^{\circ}$ heated ${ }^{\circ}$ capillary $^{\circ}\left[31{ }^{\circ} .{ }^{\circ}\right.$ In $^{\circ}$ this ${ }^{\circ}$ region, ${ }^{\circ}$ the ${ }^{\circ}$ electrospray particles move with the velocity of sound $(\sim 300 \mathrm{~m} / \mathrm{s})$ as a result of the free jet expansion into the vacuum. For the 150-kDa ions of antibody, this velocity corresponds to a relatively high kinetic energy of $\sim 60$ $\mathrm{eV}$. It required a larger focusing potential $(\sim 100 \mathrm{~V})$ provided by the tube lens to focus the ions into the orifice of the skimmer. In addition, we believe that another factor to consider is the dissociation of ion in the nozzle/skimmer region, as was pointed out by

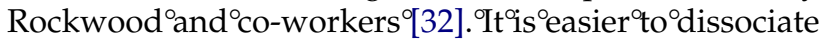
highly charged ions by acceleration in the nozzle/ skimmer because of at least two factors. First, because they are more highly charged, they acquire more kinetic energy by being accelerated. Second, highly charged ions tend to be inherently less stable because Coulombic repulsion destabilizes them, making it easier to break ions into fragments. Therefore, if the potential voltage drop is set too high, loss of ions will occur because they will dissociate, especially for highly charged ions. Thus, the voltage drop potential in the nozzle/skimmer needs to be high enough to desolvate intact antibody ions, but not so high as to dissociate them.

\section{Conclusions}

We have demonstrated, for the first time, that intact 150-kDa monoclonal antibodies and their potential degradation products could be characterized by electrospray ionization using a standard commercial threedimensional ion-trap mass spectrometer coupled online with RP-HPLC (IT-LC/MS). To the best of our knowledge, these $150-\mathrm{kDa}$ antibodies are the largest proteins detected by an unmodified ion-trap mass spectrometer thus far. In this report, we focused our applications on a POROS analytical column to accomplish our objectives of determining molecular masses of antibodies. A combination of employing the nontraditional solvent systems and optimizing the transfer efficiency of the sample by lowering the tube lens offset voltages of the QIT led to the successful development of this "Trap for MAbs" method. We anticipate that the chromatographic peak resolutions as well as the sensitivity of the mass spectrometer can be substantially improved with either narrow bore POROS columns or other commercially available columns or other solvent systems. The analysis of intact antibodies in protein pharmaceutics opens a new field of applications for three dimensional ion trap mass spectrometry, which, until recently, has been considered as mainly a tool for peptide mapping of proteins after their enzymatic digestion.

\section{Acknowledgments}

The authors thank Drs. Bruce Kerwin and Michael Treuheit for providing sTNF-R1 protein for calibration and chimeric antibody samples. They also thank Drs. Robert Rush, Alan L. Rockwood, and David Brems for insightful suggestions and reviewing of this manuscript. Preliminary results of this investigation were presented at the 52nd ASMS Conference on Mass Spectrometry and Allied Topics, Nashville, TN, May 22-27, 2004.

\section{References}

1. Clark, M. R. Antibody Humanization: A Case of the "Emperor's new clothes". Immunol. Today. 2000, 21(8), 397-420.

2. Lewis, D. A.; Guzzetta, A. W.; Handcock, W. S. Characterization of Humanized Anti-Tac, an Antibody Directed Against the Interleukin 2 Receptor, Using Electrospray Ionization Mass Spectrometry by Direct Infusion LC/MS and MS/MS. Anal. Chem. 1994, 66, 585-595.

3. Fenn, J. B.; Mann, M.; Wang, C. K.; Wong, S. F.; Whitehouse, C. M. Electrospray Ionization for Mass-Spectrometry of Large Biomolecules. Science 1989, 246, 64-71.

4. Wilm, M. S.; Mann, M. Analytical Properties of the Nanoelectrospray Ion Source. Anal. Chem. 1996, 68, 1-8.

5. Le, J. C.; Hui J.; Haniu M.; Katta, V.; Rhode, M. F. J. Development and Evaluation of On-Line Nanoliter Flow Analysis of Proteins Digests by Pneumatic-Splitter Electrospray Liquid Chromatography Mass Spectrometry. J. Am. Soc. Mass Spectrom. 1997, 8, 703-712. 
6. Valaskovic, G. A.; Kelleher, N. L.; Little, D. P.; Aaserud, D. J.; McLafferty, F. Attomole-Sensitive Electrospray Source for Large-Molecule Mass Spectrometry. Anal. Chem. 1995, 67, 3802-3805.

7. Alexander, J. A.; Hughes, E. D. Monitoring of IgG Antibody Thermal Stability by Micellar Electrokinetic Capillary Chromatography and Matrix-Assisted Laser Desorption/Ionnization Mass Spectrometry. Anal. Chem. 1995, 67, 3626-3632.

8. Downard, K. M. Contributions of Mass Spectrometry to Structural Immunology. J. Mass Spectrom. 2000, 35, 493-503.

9. Verentchikov, A. N.; Ens, W.; Standing, K. G. Reflecting Time-of-Flight Mass Spectrometer with an Electrospray Ion Source and Orthogonal Extraction. Anal. Chem. 1995, 66, 126-133.

10. Tito, M. A.; Tars, K.; Valegard, K.; Hajdu, J.; Robinson, C. V. Probing Molecular Interaction in Intact Antibody: Antigen Complexes, an Electrospray Time-of Flight Mass Spectrometry Approach. Biophys. J. 2001, 81, 3503-3509.

11. Robert, G. D.; Johnson, W. P.; Burman, S.; Anumula, K. R.; Carr, S. A. An integrated Strategy for Structure Characterization of the Protein and Carbohydrate Components of Monoclonal Antibodies: Application to Anti-Respiratory Syncytial Virus MAB. Anal. Chem. 1995, 67, 3613-3625.

12. Bennett, K. L.; Smith, S. V.; Lambrecht, R. M.; Truscott, R. J. W.; Sheil, M. M. Rapid Characterization of ChemicallyModified Proteins by Electrospray Mass Spectrometry. Bioconj. Chem. 1996, 7, 16-22.

13. Masuda, K.; Yamaguchi, Y.; Kato, K.; Takahashi, N.; Shimada, I.; Arata, Y. Pairing of Oligosaccharides in the Fc Region of Immunoglobulin G. FEBS Lett. 2000, 473, 349-357

14. Le, J. C.; Bondarenko, P. Trap for MAbs: Novel Approach to Characterize Intact Antibodies and Degradation Products Using RP-HPLC and Ion-Trap Mass Spectrometry. Proceedings of the 52nd ASMS Conference; Nashville, TN, May 2004.

15. Dillon, T. M.; Speed Ricci, M.; Rehder, D.; Pipes, G.; Zhang, Y.; Stackhouse, N.; Huinker, A.; Treuheit, M. J.; Bondarenko, P. V. Rapid LC/MS Method for Monitoring and Characterizing Intact Therapeutic Monoclonal Antibodies. Proceedings of the 52nd ASMS Conference; Nashville, TN, May, 2004.

16. Dillon, T. M.; Bondarenko, P. V.; Speed Ricci, M. Development of an Analytical Reversed-Phase High-Performance Liquid Chromatography-Electrospray Ionization Mass Spectrometry Method for Characterization of Recombinant Antibodies. J. Chromatogr. A 2004, 1053, 299-305.

17. Eris, T.; Liu, J. Reversed Phase HPLC/MS Method for Analysis of Post-Translational Modification of Monoclonal Antibody in Cell Culture Media. Proceedings of the 50th ASMS Conference; Orlando, FL, June, 2002.

18. Battersby, J. E.; Snedecor, B.; Chen, C.; Champion, K. M.; Riddle, L.; Vanderlaan, M. Affinity Reversed Phase Liquid Chromatography Assay to Quantitate Recombinant Antibodies and Antibody Fragments in Fermentation Broth. J. Chromatogr. A 2000, 972, 61-76.
19. Apffel, A.; Fischer, S.; Goldberg, G.; Goodley, P. C.; Kuhlmann, F. E. Enhanced Sensitivity for Peptide Mapping with Electrospray Liquid Chromatography-Mass Spectrometry in the Presence of Signal Suppression Due to Trifluoroacetic Acid-Containing Mobile Phases. J. Chromatogr. A 1995, 712, 177-190.

20. Medzihradszky, K. F.; Maltby, D. A.; Hall, S. C.; Settineri, C. A.; Burlingame, A. L. Characterization of Protein O-Glycosylation by Reversed-Phase Microbore Liquid Chromatography/Electrospray Mass Spectrometry, Complementary Mobile Phases, and Sequential Exoglycosidase Digestion. J. Am. Soc. Mass Spectrom. 1994, 5, 350-358.

21. Paul, W.; Steinwedel, H. German Pattent 944900; 1956. U.S. Patent 2939 952; 1960.

22. Paul, W. Electromagnetic Traps for Charged and Neutral Particles (Nobel lecture). Angew. Chem. 1990, 29, 739-748.

23. March, R. E. An Introduction to Quadrupole Ion Trap Mass Spectrometry. J. Mass Spectrom. 1997, 32, 351-369.

24. Stafford, G. C., Jr.; Kelley, P. E.; Syka, J. E. P.; Reynolds, W. E.; Todd, J. F. J. Recent Improvements in Analytical Application of Advanced Ion-Trap Technology. Int. J. Mass Spectrom. Ion Processes 1984, 60, 85-98.

25. Mcluckey, S. A.; Van Berkel, G. J.; Goeringer, D. E.; Glish, G. L.; Ion Trap MS of Externally Generated Ions. Anal. Chem. 1994, 66, 689-696.

26. Fountain, S. T.; Lee, H.; Lubman, D. M. Mass-Selective TOF-MS with Ion-Trap Storage. Rapid Commun. Mass Spectrom. 1994, 68, 487-494.

27. Cai, Y.; Peng, W. P.; Chang, H. C. Ion Trap Mass Spectrometry of Fluorescently Labeled Nanoparticles. Anal. Chem. 2003, 75, 1805-1811.

28. Guan, S.; Marshall A. G. Equilibrium Space Charge Distribution in a Quadrupole Ion Trap. J. Am. Soc. Mass Spectrom. 1994, $5,64-71$.

29. Harris, R. J.; Kabakoff, B.; Macchi, F. D.; Shen, F. J.; Kwong, M. Y.; Andya, J. D.; Shire, S. J.; Bjork, N.; Totpal, K.; Chen, A. B. Identification of Multiple Sources of Charge Heterogeneity in a Recombinant Antibody. J. Chromatogr. B Biomed. Sci. Appl. 2001, 752, 233-245.

30. Jones, M. D.; Hunt, J.; Liu, J. L.; Patterson, S. D.; Kohno, T.; Lu, H. S. Determination of Tumor Necrosis Factor Binding Protein Disulfide Structure: Deviation of the Fourth Domain Structure from the TNFR/NGFR Family Cysteine-Rich Region Signature. Biochemistry 1997, 36, 14914-14923.

31. Mylchreest, I. C., Hail,, M. E., Herron,, J. R. Method and Apparatus for Focusing Ions in Viscous Flow Jet Expansion Region of an Electrospray Apparatus. Thermo Finnigan U.S. Patent 5157260; 1992.

32. Rockwood, A. L.; Busman, M.; Smith, R. D. Coulombic Effects in the Dissociation of Large Highly Charged Ions. Int. J. Mass Spectrom. Ion Processes 1991, 111, 103-129. 